\title{
- Processo de Difusão de Inovações em Produtos Bancários
}

\author{
Júlio F. B. Facó ${ }^{1}$ \\ Eduardo H. Diniz ${ }^{2}$ \\ João Mario Csillag ${ }^{3}$
}

\section{Resumo}

Esta pesquisa investiga em profundidade o processo de criação e difusão de novos produtos no setor bancário. A pesquisa propõe um modelo de abordagem para avaliação da difusão de inovação em produtos bancários baseado em um framework de três variáveis (regulação, mercado e tecnologia) e quatro dimensões que se relacionam com a difusão de uma inovação (determinantes, ritmo, direção e implicações). A pesquisa fez uso de estudos de caso de grandes bancos de varejo operando no Brasil. Foram analisados em detalhes o processo de criação, difusão e sustentação de três novos produtos bancários face ao framework proposto. A análise do processo da difusão das inovações estudadas permitiu verificar e testar evidências do papel das variáveis e dimensões propostas no framework para sua mensuração, mostrando-se adequada ao estudo de difusão de inovações.

Palavras-chave: Inovação. Processo de Difusão. Setor Bancário.

\section{Introdução}

Produtos e serviços representam a conciliação dos recursos operacionais com os requerimentos de mercado, cujo objetivo é a continuidade de um negócio (SLACK; LEWIS, 2002). Tal conciliação é determinada pelas estratégias de gerenciamento do negócio, afetando diretamente a forma como os produtos e serviços são criados e apresentados ao mercado.

\footnotetext{
${ }^{1}$ Doutor e Mestre em Administração de Empresas com ênfase em Inovação em Cadeia de Suprimentos e Operações. Professor na ESAGS (Escola Superior de Administração e Gestão) e FECAP (Fundação Escola de Comércio Álvares Penteado). Endereço: Rua Universal, 212 São Bernardo do Campo - SP - CEP 09608-000. E-mail: julio.faco@gmail.com.

${ }^{2}$ Doutor e Mestre em Administração de Empresas. Professor na EAESP/FGV (Escola de Administração de Empresas de São Paulo). Endereço: Rua Itacolomi, 200, ap 31 Higienópolis, São Paulo - SP - CEP 01239-020. E-mail:eduardo.diniz@fgv.br.

${ }^{3}$ Doutor e Mestre em Administração de Empresas, atua como professor na EAESP/FGV, vice-presidente de relações internacionais da Associação Brasileira de Engenharia e Análise de Valor, membro do conselho consultivo do Instituto Paulista de Excelência de Gestão e membro do conselho diretor do Instituto Mauá de Tecnologia. Endereço: EAESP/FGV-Depto POI. Av. 9 de Julho, 2029, São Paulo - SP CEP 01313-902. E-mail: joao.mario.csillag@fgv.br. Artigo recebido em: 10/12/2008. Aceito em: 30/08/2009. Membro do Corpo Editorial Científico responsável pelo processo editorial: Martinho Isnard Ribeiro de Almeida.
} 
Júlio F. B. Facó • Eduardo H. Diniz • João Mario Csillag

Schilling e Hill (1998), Clausing (1994), Clark e Wheelwright (1993) e Clark e Fujimoto (1991) alertam para o fato de o processo de desenvolvimento de produtos ser da mais alta prioridade para o sucesso da empresa. A orientação das empresas em busca da efetividade no desenvolvimento do produto é uma das responsabilidades da alta gestão e deve passar, necessariamente, pelo estabelecimento de estratégias de posicionamento no mercado e pela implementação de práticas ou procedimentos que maximizem o desempenho do processo de desenvolvimento de inovações (GRIFFIN, 1997; VAN DE VEN, 1986). Além disso, as inovações podem ser empregadas tanto para incremento de receita, quanto para conquista ou retenção de clientes (CHAKRAVORTI; KOBOR, 2003; BROWN; EISENHARDT, 1995). Assim, esta pesquisa tem em seu foco o estudo do processo de difusão de produtos inovadores, com uma análise particular no setor bancário brasileiro, apresentando detalhes desse processo para três produtos considerados inovadores pelo segmento.

Uma breve revisão teórica acerca da difusão de inovações (e temas correlatos) é apresentada nas Seções 2, 3 e 4. Particularmente nas seções 3 e 4 a pesquisa propõe um modelo de abordagem para avaliação da difusão de inovação em produtos bancários baseado em um framework de três variáveis (regulação, mercado e tecnologia) e quatro dimensões que se relacionam com a difusão de uma inovação (determinantes, ritmo, direção e implicações). A Seção 5 apresenta detalhes do método utilizado para a coleta de dados. Por fim, o teste, aplicação, discussão do framework proposto e conclusão são apresentados nas Seções 6, 7 e 8, com o anexo contendo os frameworks aplicados às três inovações.

\section{Difusão de Produtos e Serviços Inovadores no Setor Bancário}

A difusão pode ser definida como "o processo pelo qual uma inovação é comunicada através de certos canais, através do tempo, entre os membros de um sistema social" (ROGERS; SCHOEMAKER, 1971, p. 18). Os processos de inovação e difusão, entretanto, não podem ser totalmente separados, segundo Tigre (2006), pois em muitos casos a difusão contribui para o processo de inovação. Dessa maneira, a difusão colabora com a própria inovação revelando oportunidades de melhoria aperfeiçoamento e trajetória. 
Estudos sobre a difusão de novos produtos no setor de serviço são menos frequentes do que no setor de bens físicos e os bancos representam um enorme potencial de pesquisa neste segmento (BARRAS, 1990; COOPER et al., 1994; DINIZ; FACÓ; CSILLAG, 2007; FACÓ; 2006).

Com relação à inovação, um novo serviço pode ser caracterizado pela soma de diversas ofertas (serviços) em um só, as alterações radicais no processo de entrega do serviço ou, ainda, melhorias incrementais em serviços existentes (METTERS et al., 2003).

É prática do mercado falar sobre produtos e serviços bancários, vez por outra tratando-os como coisas distintas, outras vezes com o mesmo sentido. Esse aspecto de tratamento, ora distinto ora com a mesma condição para produtos e serviços bancários, também já havia sido observado por Leite (1996).

Todavia, vale ressaltar que produtos e serviços são comumente diferenciados pela argumentação de que eles são em geral intangíveis (não podem ser estocados e nem testados antes de ser adquiridos), heterogêneos (demandam maior personalização e interação com os clientes) e inseparáveis (são produzidos e consumidos ao mesmo tempo).

Por essas definições, um produto bancário seria na verdade sempre um serviço. Reforçando a ideia de que tais fatores não são suficientes para definir a diferenciação (CORRÊE; CORRÊEA, 2006). O mercado bancário, que é de serviços por excelência, já superou na prática essa barreira: os assim chamados produtos bancários mais comuns são em geral intangíveis (conta corrente, por exemplo), heterogêneos (fundos e carteiras de aplicações) e inseparáveis (empréstimos).

Tendo fortes características de serviços, o processo de difusão de produtos bancários também pode ser analisado utilizando modelos de difusão de serviços. Um estudo das características das inovações tecnológicas na área de serviços (BARRAS, 1990) apresenta o ciclo de inovação de forma antagônica ao ciclo de inovação na área de produtos e bens físicos. Na área de produtos, a primeira etapa do ciclo inovador caracteriza-se pelas inovações de produto, a isso se segue uma segunda etapa, na qual é possível verificar inovações radicais de processo, e, na última etapa, predominam as inovações incrementais de processo. Na área de serviços, na primeira etapa, observam-se inovações incrementais de processo, na segunda etapa surgem as inovações radicais do processo e na última etapa encontram-se as inovações de produto. 
Júlio F. B. Facó • Eduardo H. Diniz • João Mario Csillag

Corrobora com essa ideia a afirmação de Andreassi (2002, p. 2):

Contrariamente à indústria, em serviços a inovação de processo precede a inovação de produto. O primeiro estágio consiste na inovação de processo, utilizando novas tecnologias geradas por outros setores para aumentar a eficiência na produção/entrega de serviços existentes. É o caso dos primeiros caixas eletrônicos bancários, com operações restritas. Em um segundo estágio, os novos sistemas de produção/entrega de serviços são utilizados para melhorar a qualidade do serviço, como o número de operações que de uns tempos para cá pode ser realizado nos caixas eletrônicos. Só em um terceiro estágio é que os novos produtos decorrentes das novas tecnologias são criados - nesse caso, são exemplos os seguros contra fraude $e$ roubo de cartão eletrônico.

Assim, por essa análise de difusão, uma nova tecnologia na área de serviços surgiria, num primeiro estágio, para melhorar a sua eficiência. Essa é também uma etapa de aprendizado da tecnologia por parte da organização e os fornecedores têm papel dominante no processo de adoção de tecnologia pela indústria usuária.

No segundo estágio, as inovações incrementais de processo tenderiam a contribuir para a melhoria da qualidade do serviço, que implica em alterações mais radicais no processo do que a simples melhoria da eficiência. As empresas, individualmente, não seguem um ritmo uniforme dentro do processo de inovação que está ocorrendo na indústria como um todo. Enquanto algumas adotam uma estratégia mais agressiva de inovação, para garantir uma liderança de mercado e tecnologia, outras adotam estratégias defensivas ou de imitação, preocupadas em aprender com os erros dos pioneiros.

O terceiro estágio caracteriza-se pelo desenvolvimento de novos produtos. Na indústria de serviços, nem sempre é simples distinguir um novo serviço de uma melhoria num serviço existente. Isso se deve à própria natureza dos serviços que são consumidos no mesmo momento em que são produzidos. Assim, o produto está, de tal forma, ligado à sua distribuição, que mudanças radicais no processo vão levar à criação de novos produtos. E a influência dessas inovações vai implicar também em alterações na estrutura organizacional das empresas. 


\section{Regulação, Mercado e Tecnologia como Dimensões de Análise da Difusão de Inovações de Produtos Bancários}

De acordo com Corrêa e Caon (2002) e Slack e Lewis (2002), uma empresa define as prioridades competitivas de acordo com o mercado e seus recursos operacionais disponíveis. Particularmente no caso de empresas do setor bancário, além do mercado e dos recursos operacionais, entre os quais pode-se destacar a tecnologia de informação, deve-se levar em conta também o quadro regulatório, devido ao controle estrito exercido sobre empresas do setor (ERIKSSON, 1994).

Assim, é possível a identificação de fatores que influenciam o surgimento e o desenvolvimento de um novo produto bancário, contribuindo para impulsionar ou restringir a sua difusão no mercado. Entre esses fatores certamente podem ser considerados aqueles relacionados à regulação do setor, fatores de mercado, como a competição e demandas de clientes, e também aplicações relacionadas à tecnologia de informação (BÁTIZ-LAZO; WOLDESENBET, 2004).

$\mathrm{Na}$ prática, os fatores regulatórios de mercado e tecnológicos se confundem, mas é didático tentar pensá-los de forma isolada. A seguir será argumentado como tais fatores podem influenciar o desenvolvimento de novos produtos no setor bancário.

\subsection{Regulação e Inovação no Setor Bancário Brasileiro}

O setor bancário está entre os mais regulamentados da economia, e fatores regulatórios podem também estar por trás do desenvolvimento da oferta de novos produtos financeiros. De um modo geral, os processos de regulação bancária objetivam tanto garantir o nível de segurança financeira do sistema quanto possibilitar a sua supervisão (LIMA, 2003). Sem entrar no mérito das motivações e justificativas que sustentam os diversos modelos de regulação do setor bancário, é importante considerar que as características reguladoras adotadas podem influenciar direta ou indiretamente na difusão de produtos e serviços inovadores neste mercado. Basta considerar que muitos produtos são desenvolvidos a partir de medidas regulatórias promovidas no interior de setores governamentais. 
Exemplos de crédito para aquisição de bens específicos, como automóveis ou residências, e financiamentos para investimentos em setores específicos, são geralmente moldados por iniciativas regulatórias originadas em esferas governamentais. Outro exemplo de produto bancário desenvolvido a partir de demanda regulatória é o microcrédito, instituído no Brasil a partir de várias leis e decretos criados em 1999 (ROSALES, 2000).

Particularmente no Brasil, onde grandes reformas têm reorientado a atuação dos bancos nos últimos 40 anos, esse impacto da regulação no desenvolvimento de produtos bancários pode ser facilmente identificado. As reformas dos anos 60 resultaram na consolidação de uma segmentação mais definida do mercado financeiro, através da especialização das funções das instituições financeiras, e da vinculação da captação com a aplicação dos recursos. Essas reformas abriram espaço para a criação de produtos e serviços inovadores, como as cadernetas de poupança e a instituição de pagamentos de contas de consumo através dos bancos.

Essa segmentação sofre um movimento reverso a partir de 1988, quando o Conselho Monetário Nacional institui os bancos múltiplos, permitindo que bancos comerciais, de investimento e sociedades de crédito se organizassem sob uma única instituição financeira. A criação dos bancos múltiplos favoreceu uma expansão da oferta de serviços financeiros. Isso feito, já sob a influência do grande avanço tecnológico do setor, a inovação nos produtos bancários começa a ficar fortemente associada ao uso de plataformas tecnológicas através dos quais os clientes passam a ter contato com os bancos. A concorrência, disponibilidade de tecnologia e também a inflação contribuem fortemente para um período de grande inovação em produtos e serviços bancários (PIRES, 1997).

Nos anos 90, os movimentos regulatórios tiveram sentido de consolidar a abertura do setor iniciada na fase anterior e também reorganizá-lo para um período de inflação baixa que se iniciava. A participação de grandes bancos estrangeiros ampliada com as medidas regulatórias do final de 1994, associadas a um novo movimento de concentração, particularmente devido a ajustes provocados pelo recuo da inflação, também influencia o desenvolvimento de novos produtos. Corroborando essa ideia, Grisci e Bessi (2004) afirmam que o ingresso de bancos estrangeiros em um país traz consigo uma nova concepção de serviço bancário com prestação de assessoria a clientes e não clientes, auxiliando a ambos na aplicação de seus recursos. 


\subsection{Mercado e Inovação no Setor Bancário}

Além dos efeitos regulatórios, o item anterior apontou também a influência de algumas variáveis de ambiente no processo de inovação no setor bancário, tais como inflação e concentração do setor.

Mudanças no mercado podem inspirar a criação de produtos financeiros específicos. Por exemplo, da análise da evolução do perfil dos consumidores levou diversas empresas do setor de seguros a criar um produto denominado "seguro da mulher", focando interesses específicos desse segmento de mercado, como por exemplo, o apoio ao tratamento de câncer de mama.

O desenvolvimento de novos produtos no setor bancário pode ser visto ainda a partir da influência dos fatores de mercado ligados tanto à oferta quanto à demanda. Pelo lado da oferta, os bancos concorrem para se diferenciar e atender a segmentos específicos de mercado, que podem ter características bastante diferentes. Pelo lado da demanda, as mudanças no perfil dos clientes dos serviços bancários também pressionam os bancos a buscarem novas alternativas de produtos e serviços que venham a satisfazer seus clientes.

Assaf (1999) afirma que os bancos segmentam a sua atuação de mercado com base no volume de negócios dos clientes e em sua forma de atendimento. Pelo volume de negócios, o perfil dos produtos bancários pode ser dividido em varejo, voltados para atender a um grande volume de clientes; e negócios ou atacado, voltados às grandes operações financeiras, focando um número reduzido de clientes com alto poder aquisitivo.

Para Rogers (1993), o negócio de varejo nos bancos é muito diferente daquele de atacado, tanto em termos de tecnologia quanto de produtos, $e$ exige cultura e administração diferentes. Ele argumenta que no varejo é necessário a tecnologia rotinizada, enquanto no atacado a tecnologia está voltada para o trabalho artesanal, a pesquisa e o desenvolvimento. Segundo ele, nos bancos de varejo a estrutura organizacional adequada é centralizada, ou seja, os produtos são desenvolvidos no topo e a estrutura de rotina burocrática prevalece nos pontos de venda. Por outro lado, no corporate bank, o desenvolvimento de produtos e a criatividade estão localizados nos pontos de distribuição, na interação com os clientes, cada qual único e com necessidades específicas.

Outro fator importante de mercado que influencia o processo de inovação nos produtos bancários é a evolução do comportamento dos consumi- 
dores. Sheth e Sisoda (1998) afirmam que as mudanças no trabalho, comunicação e opções de lazer das pessoas exercem pressão nas empresas para mudar a maneira de fazer negócios. Em nenhum ambiente empresarial isso é mais verdadeiro do que nos bancos.

Stern, El-Ansary e Coughlan (1996) afirmam que existem claramente dois mecanismos de forças direcionadoras do interesse dos consumidores pela prestação de serviços financeiros de forma eletrônica: uma nova definição de conveniência por parte dos consumidores e o impacto da tecnologia no comportamento dos consumidores.

Sheth e Sisoda (1998) e Popcorn (1994) apontam o encasulamento (tendência a refugiar-se em casa), a valorização do tempo e a busca pela conveniência como importantes tendências de mudança no comportamento dos consumidores que, no contexto da economia digital e do mercado virtual, estão relacionadas com a utilização da Internet como canal de distribuição, tanto de produtos quanto de serviços, particularmente os financeiros.

\subsection{Tecnologia e Inovação no Setor Bancário}

Não há dúvidas quanto à importância do papel da tecnologia de informação no processo de desenvolvimento de inovações no setor bancário. A tecnologia participa tanto do processo de criação de produtos, quanto de sua distribuição aos clientes. Mesmo inovações tecnológicas que surgem no mercado sem relação direta com o setor podem influenciar o processo de criação de novos produtos bancários. Um produto originado de uma inovação tecnológica externa ao universo bancário, por exemplo, o telefone celular, pode determinar a criação de um produto bancário específico - acesso remoto via celular aos dados bancários do cliente.

No que diz respeito à inovação em processos de distribuição de produtos, o impacto é geralmente maior nos produtos ligados ao varejo bancário, como já foi visto no item anterior. Produtos voltados para o varejo são muito mais propícios para serem capturados através de sistemas e oferecidos via canais de autoatendimento, que podem variar muito segundo as tecnologias disponíveis. 
A Figura 1 mostra a evolução das transações bancárias para os diversos canais no período entre 1997 e 2006 ${ }^{4}$, indicando a evolução do volume de transações por canal. Percebe-se claramente a importância dos canais eletrônicos para os bancos, tanto no volume de transações quanto na taxa de crescimento. Basta dizer ainda que os canais eletrônicos representam hoje no país quase $80 \%$ do volume total de transações.

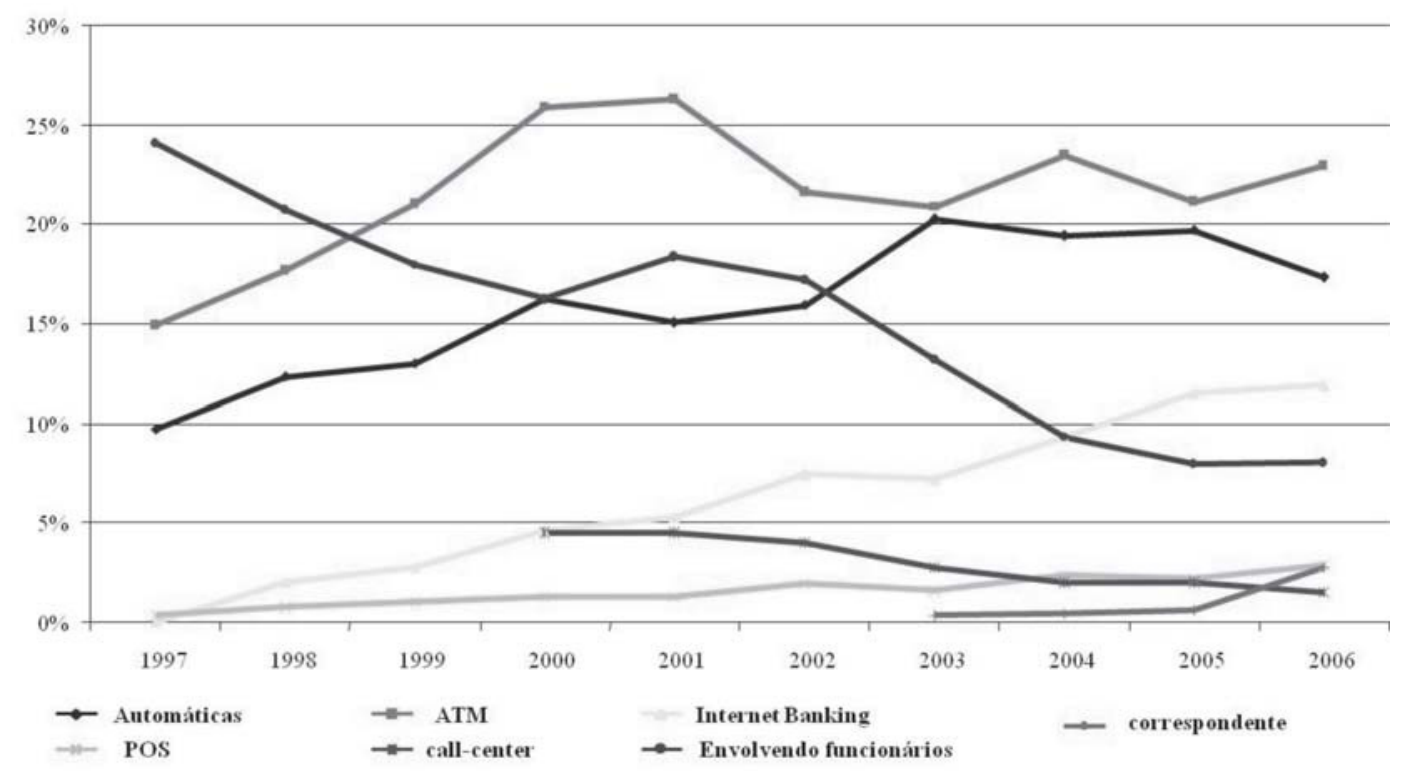

Figura 1: Evolução dos canais bancários no Brasil.

Fonte: Adaptada de Febraban (2008).

Os canais eletrônicos, que podem ser eles mesmos inovadores, são também os mais propícios também para a distribuição de novos produtos. Além dos já consolidados caixas eletrônicos e Internet, que possui um impacto muito forte em toda a estrutura do negócio bancário, a telefonia celular está hoje na mira de todos os grandes bancos, que já veem os mais de 80 milhões de aparelhos disponíveis em mãos de clientes reais e potenciais, como o dispositivo que tende a trazer maior inovação no processo de distribuição de serviços bancários.

\footnotetext{
${ }^{4}$ ATM está relacionado com os caixas automáticos; automáticas são operações como cobrança de CPMF ou outras, por exemplo; nas automáticas externas estão as operações de débito automático; POS (point-of-sale) são operações relacionadas com cartões de débito; callcenter são transações automáticas feitas através de telefone.
} 
Enquanto no mercado de varejo predomina a padronização, para o atacado o nível de customização é muito maior. Da mesma forma, os bancos se dirigem ao mercado de atacado através de processos menos estruturados do que acontece quando se trata do mercado de varejo. Mas tecnologias mais ligadas aos processos de análise interna de negócio também contribuem para o desenvolvimento de novos produtos,

Nesse contexto, a criação e a disponibilização de produtos bancários depende de implementação de tecnologias e sistemas, que não deixam de ser processos de negócio encapsulados e claramente identificados. A tecnologia no setor bancário é utilizada para dar suporte tanto na criação, quanto na distribuição ou no aperfeiçoamento de um novo produto.

\section{Dimensões de Análise na Difusão de Inovação em Produtos Bancários: determinantes, ritmo, direção e implicações}

Além de identificar os determinantes na criação de produtos, ainda através da observação da influência dos mesmos fatores (mercado, tecnologia e regulação), pode-se também estudar a evolução dos novos produtos, avaliando assim a difusão de uma inovação. Assim, questões propostas para o estabelecimento de uma análise sobre difusão de produtos inovadores envolvem a identificação de:

a) motivações que originaram a criação dos novos produtos (determinantes);

b) o quanto a oferta desses produtos está evoluindo (ritmo);

c) como os produtos estão se desenvolvendo (direção); e

d) quais os impactos que os produtos estão provocando (implicações).

\subsection{Determinantes}

Uma inovação tecnológica começa com a adoção de um novo produto, processo ou sistema num ambiente de negócios e mantém a sua difusão entre uma determinada população de usuários (HUSSEY, 1997; MCLOUGHLIN; 
HARRIS, 1997). Essa difusão é também uma combinação do fato da inovação ser tanto empurrada pela tecnologia (technology-pushed) quanto puxada por uma demanda do mercado (market-pulled).

Após a entrada de alguns pioneiros no segmento, oferecendo serviços bancários básicos, como, por exemplo, consulta a informações sobre contas e possibilidade de transferências de fundos através da Web, a confiança na segurança da Internet para transações bancárias gradativamente aumentou. É de se destacar a demanda dos usuários dos serviços bancários pela comodidade da utilização do canal Web, o que acabou por influenciar os investimentos dos bancos.

O sucesso dos pioneiros acabou por empurrar os concorrentes na busca de manutenção da base de clientes. Ao mesmo tempo em que crescia a adesão dos bancos à Web banking, percebeu-se que quem não estivesse oferecendo esse tipo de serviço poderia perder clientes, fazendo engrossar mais ainda a massa de bancos oferecendo transações pela Internet.

Para os bancos, por causa da maior confiança na segurança oferecida pela Internet, a estratégia de usar a Web como um canal para transações, poderia trazer também economia no processamento de serviços bancários usualmente realizado em outros canais. Entretanto, a economia real só virá com um crescimento muito expressivo da utilização da Web, quando ela rivalizar com os outros canais de distribuição de serviços bancários ainda hoje predominantes.

No entanto, a Web pode também ser explorada para ampliar o relacionamento com os atuais clientes, com o objetivo de desenvolver serviços que sejam mais apropriados às suas necessidades e também de oferecer aos clientes de alta rentabilidade para o banco mais produtos entre os já disponíveis na carteira (cross-selling). Conhecendo melhor os clientes, os bancos, além de poderem saber quais os seus produtos de maior rentabilidade, poderiam também conhecer os clientes mais vantajosos para a empresa $e$ explorá-los de forma mais profícua.

\subsection{Ritmo}

Uma análise de difusão não pode prescindir da avaliação da velocidade com que a inovação é adotada num determinado meio. Trajtenberg et al. (1989) ressalta a importância de avaliar ritmo como sendo uma das formas 
Júlio F. B. Facó • Eduardo H. Diniz • João Mario Csillag

de comprovar a natureza do processo de difusão e o ritmo de adoção de uma inovação.

No caso específico dos bancos, o ritmo de difusão está relacionado com a aquisição, distribuição, retenção e recuperação do conhecimento necessário para o desenvolvimento de novos processos (McKENDRICK, 1995).

Comparando os inovadores com os imitadores, dentro da busca por soluções para reformular os processos bancários, os primeiros costumam buscar, em um número maior de canais, as alternativas para melhorar os seus processos, ainda que essas fontes de imitação sejam geralmente informais. Isso porque os fatores que determinam a busca de know-how sobre um processo dentro de uma indústria estão além das exigências técnicas específicas da indústria. A intervenção regulatória, por exemplo, tem importantes implicações para o desenvolvimento, a base de conhecimento, o tamanho e o foco competitivo de uma empresa no setor.

\subsection{Direção}

A análise da direção dos desenvolvimentos também precisa ser levada em conta quando se analisa difusão das inovações. Nesse sentido, dois estudos se apresentam muito apropriados a esse tema e são apresentados por Barras (1990) e Hanna et al. (1995).

No primeiro estudo, o autor propõe um ciclo de inovação a partir de observações empíricas, de forma antagônica ao ciclo de inovação na área de produtos e bens físicos. Enquanto para bens físicos o ciclo inovador inicia-se com inovações de produto, seguidas de inovações radicais de processo, e, por fim, de inovações incrementais de processo. Na área de serviços, observa-se o inverso. A primeira fase do ciclo de inovações é caracterizada por inovações incrementais de processo, a partir das quais surgem inovações radicais do processo dando origem por fim às inovações de produto.

Por sua vez, Hanna et al. (1995) complementam a teoria de ciclo de inovações em serviços propondo também três fases de difusão de uma nova tecnologia em processos. A primeira fase ocorre quando a nova tecnologia meramente substitui a existente, sem ter maiores implicações no processo envolvido. Na segunda fase, a nova tecnologia pode induzir a uma substancial melhoria de performance no processo. E a terceira fase ocorre quando a nova tecnologia abre a oportunidade para a transformação dos processos $e$ 
das estruturas organizacionais. As barreiras para adoção da tecnologia dependem de cada uma dessas fases para uma tecnologia particular que esteja sendo considerada.

Com base nesses dois estudos anteriores, verifica-se que no caso particular do Web banking, a direção de sua evolução aponta para o investimento na criação de serviços on-line, que explorem recursos específicos da Web, adequando assim as necessidades dos usuários que se utilizam desse canal aos interesses do banco. A lógica do investimento em serviços mais interativos justifica-se pela necessidade de atender a uma demanda de usuários cada vez mais familiarizados com o uso da Web para as mais diversas atividades. Além disso, os serviços mais interativos propiciam ao banco a exploração de serviços inovadores, que podem criar novas oportunidades de negócios.

\subsection{Impactos}

Apesar dos estudos de difusão de tecnologia serem comumente focados no setor manufatureiro (BUZZACHI et al., 1995), dentro do setor de serviços os bancos representam o segmento que mais tem experimentado mudanças devido à introdução de novas tecnologias. Por serem os principais usuários de Tecnologia de Informação - TI, os bancos se transformam assim no setor mais atraente para o estudo de inovação tecnológica em serviços, embora haja divergência entre autores sobre as características dessas transformações, que consideram ora evolucionárias (BARRAS, 1990), ora revolucionárias (BUZZACHI et al., 1995).

Num outro estudo sobre como a inovação tecnológica pode alterar a lógica funcional do serviço, Betz (1993) destaca quatro problemas centrais na implementação de novas tecnologias em serviços: 1) conseguir a relação custo/performance adequada no projeto do serviço com a nova tecnologia; 2) determinar o melhor foco de aplicação para um serviço com a nova tecnologia; 3) determinar as exigências e especificações apropriadas para um serviço usando a nova tecnologia; e 4) decidir onde deve estar a vantagem competitiva que é proprietária da empresa.

A utilização de novas tecnologias pelos bancos, no entanto, nem sempre está relacionada com o aumento de produtividade (EDWARDS, 1995). Num período de rápidas mudanças tecnológicas, as empresas acabam por investir muito pesadamente na reposição de equipamentos e tecnologias que 
Júlio F. B. Facó • Eduardo H. Diniz • João Mario Csillag

ficam obsoletas rapidamente. Além disso, as mudanças na distribuição e organização do trabalho, provocadas pelas novas tecnologias, resultam inicialmente em "deseconomias", que só podem ser corrigidas com o tempo e a experiência.

Gonçalves (1994) divide os impactos da introdução de inovações entre aqueles que interferem nos aspectos físicos das organizações, os que interferem no aspecto psicológico das pessoas envolvidas e os que alteram o trabalho. Embora seu estudo não tivesse focado o aspecto macro, ele menciona que o impacto de inovações pode extrapolar os limites da empresa, interferindo no mercado e na economia. Outro ponto interessante desse estudo é a identificação de que os impactos de uma inovação não ocorrem apenas depois da sua introdução na empresa, mas também durante o processo de implantação e até mesmo antes, quando investimento, estratégia, planejamento e aspectos psicológicos começam a ser afetados ainda na fase de estudos sobre a introdução da inovação.

\section{O Estudo: os bancos e os produtos inovadores}

Esta investigação é de caráter qualitativo e utilizou o método de estudo de casos na condução de sua investigação. Segundo Yin (1988, p. 22-23), a essência do estudo de caso é "a tentativa de iluminar uma decisão ou conjunto de decisões: por que elas foram tomadas, como foram implementadas e com que resultado". Diz o autor que um estudo de caso é uma indagação empírica, que

[...] investiga um fenômeno contemporâneo dentro de um contexto real, quando [...] os limites entre o fenômeno e o contexto não estão claramente evidentes e no qual [...] fontes múltiplas de evidência são utilizadas (p. 23).

O estudo de caso prestou-se não só para verificar os conceitos analisados, mas também para revelar alguns aspectos que, à primeira vista, passariam despercebidos.

Uma etapa complexa deste trabalho foi a escolha do caso a estudar. Por um lado, desejava-se uma empresa que não só tivesse reconhecida liderança em termos de tecnologia, como também que fosse representativa no cenário 
bancário brasileiro. Outra característica desejável era a facilidade de acesso às informações, não só através de publicações, mas principalmente pela abertura voluntária das portas do banco aos pesquisadores.

Isso posto, os bancos escolhidos foram:

a) O Banco A, multinacional europeia presente no Brasil e que figura entre os cinco principais bancos do país. Especificamente à análise de suas áreas de Desenvolvimento de Novos Produtos.

b) $\mathrm{O}$ Banco $\mathrm{B}$, multinacional de origem brasileira e que figura entre os cinco principais bancos do país. Especificamente à análise de suas áreas de Desenvolvimento de novos Produtos.

\subsection{Metodologia de Levantamento de Dados}

O levantamento da realidade, no estudo de caso, não seria facilmente padronizável. Definiu-se então que não haveria um questionário, mas sim um roteiro de entrevista.

A partir das questões desse roteiro executou-se, nos Bancos, um ciclo de entrevistas, envolvendo diversas pessoas: executivos, gerentes e pessoal de nível técnico. Em contrapartida, um roteiro tem o inconveniente de se transformar numa armadilha para o pesquisador. Por um lado, as perguntas são tão amplas e abertas que podem levar à perda do foco; por outro, correse o risco de obter uma resposta superficial e o entrevistado dar por concluída sua participação.

Por isso foram tomados alguns cuidados para minimizar esses riscos. Em primeiro lugar, os mesmos pesquisadores conduziram todos os contatos, reduzindo a possibilidade de viés de interpretação. Os pesquisadores mantiveram-se atentos para derivar novas perguntas a partir das respostas obtidas e sempre se teve em mente o objetivo e o foco da pesquisa. Assim, conseguiu-se de cada entrevistado um amplo envolvimento.

Ademais, sempre que possível, foram feitas visitas aos Bancos e às suas áreas de desenvolvimento de produtos, observando-se seus processos. Pôdese delinear um quadro muito mais preciso e detalhado sobre os reais reflexos da inovação e do desenvolvimento de produtos, aliado à visão estratégica, também com um enfoque ao nível das operações. 
Júlio F. B. Facó • Eduardo H. Diniz • João Mario Csillag

\section{Resultados Obtidos da Análise de Difusão de Produtos Bancários Inovadores}

Pelo fato de temas relacionados à sustentabilidade ser uma das bandeiras principais do Banco $A$ na atualidade, é natural que suas inovações em produtos e serviços também se "mimetizassem" com esse tópico, alinhando assim as inovações mais recentes à estratégia do Banco.

Por sua vez o Banco B, por meio de sua nova orientação estratégica no início do Século XXI identificou uma nova oportunidade de relacionamento com seus clientes no varejo e é disso que trata essa inovação.

\subsection{Inovação no Banco $A$}

Antes, porém, de detalhar as inovações no Banco A, é necessário uma caracterização de produto bancário segundo o próprio Banco.

Produto Bancário, para o Banco A, é o meio de viabilizar soluções financeiras para atender às necessidades dos clientes do Banco.

Por sua vez, o desenvolvimento de novos produtos é uma atividade importante para o banco na medida em que está alinhado com sua estratégia de estreitar o relacionamento com seus clientes promovendo uma maior personalização de seus produtos. Além do fato do ambiente em que o Banco está inserido ser fortemente marcado por competição, em que os novos produtos desempenham papel importante na manutenção e conquista de clientes.

O Banco A para esse mesmo desenvolvimento se utiliza de uma ferramenta de TI de suporte e acompanhamento de todo o processo. Essa ferramenta é algo recente no Banco, pois começou a ser utilizada em 2005 e traz consigo uma metodologia detalhada de aplicação para dar suporte ao desenvolvimento das inovações no Banco.

O Banco A possui dois produtos que são particularmente interessantes em termos de inovação. Ambos são produtos socioambientais: a) CDC socioambiental e b) Operações de Crédito Carbono Internacionais.

O CDC socioambiental é um crédito direto ao consumidor sob a égide da sustentabilidade, presente no Banco desde 2004. Para o Banco essa questão é tratada como estratégica e existe uma Superintendência específica para esses tipos de produtos considerados produtos ligados à sustentabilidade. Tal superintendência é responsável pelo desenvolvimento e pela gestão de 
produtos socioambientais. Como exemplos de CDC socioambiental, podese citar: CDC de Kit gás (GNV) para automóveis; CDC de Pós-graduação; $\mathrm{CDC}$ de computador para professores.

As Operações de Crédito Carbono tiveram início em meados de 2005. Essas operações e ações são ligadas ao protocolo de Kyoto. O Banco Central do Brasil ainda não as reconhece como operações financeiras e, por isso, ainda estão sendo regulamentadas pelo $\mathrm{BCB}$ em parceria com o Ministério do Meio Ambiente por iniciativa do próprio Banco A

Com relação ao tempo do desenvolvimento até o lançamento dos dois produtos, tem-se:

a) O Produto Crédito Carbono levou cerca de dois anos em desenvolvimento para poder ser disponibilizado ao mercado; $e$

b) O CDC socioambiental levou quatro meses para ser desenvolvido.

Observou-se que no desenvolvimento dos produtos, a fase que exige maior emprego de tempo é o alinhamento do produto à estratégia da organização. Nesse sentido, a definição do conceito do produto é crucial e é essa fase que demanda mais tempo no desenvolvimento da inovação.

Analisado sob as dimensões de difusão das inovações propostas na parte teórica: Determinantes, Ritmo, Direção e Implicações versus Regulação, Mercado e Tecnologia tem-se o framework, para ambos os produtos, apresentado no anexo. Vale ressaltar os principais aspectos do ponto de vista de regulação, mercado e tecnologia:

a) Regulação: para o CDC já existe uma regulamentação padrão para produtos $\mathrm{CDC}$, entretanto o Banco pode criar a finalidade que desejar para o CDC; para as operações de Crédito Carbono o Banco foi tão pioneiro que iniciou o processo de normatização e regulação junto ao $\mathrm{BCB}$ e ao Ministério do Meio Ambiente, pois ainda não havia nenhuma orientação para essas operações e, no entanto, já havia ações do Banco A e clientes que demandavam tais produtos.

b) Mercado: o CDC socioambiental exigiu um trabalho do Banco de "capacitação" e esclarecimento da demanda, pois essa demanda precisava amadurecer em relação ao tema sustentabilidade; por sua vez, as Operações de Crédito Carbono foram fortemente impulsionadas pela demanda não apenas local, mas também mundial, que 
Júlio F. B. Facó • Eduardo H. Diniz • João Mario Csillag

estava disposta a realizar essas transações desde a assinatura do tratado de Kyoto.

c) Tecnologia: é essencial para ambos os produtos, entretanto seu papel se restringe ao de viabilizar (e não é vista como limitadora pela área de desenvolvimento de produtos socioambientais) das aplicações e difusão dos produtos.

Com relação aos fatores Determinantes, de Ritmo, de Direção e de Implicações das difusões de inovação, tem-se:

a) Determinantes: a tecnologia e o mercado, no papel dos clientes e concorrentes, atuam com mais presença nessa dimensão do que a regulação. Fomentando iniciativas de novos produtos, seja por influência da demanda ou da concorrência, ou por uma nova disponibilidade tecnológica que pode viabilizar o advento de um novo produto.

b) Ritmo: essa dimensão é fortemente marcada pelas informações do mercado (particularmente dos concorrentes) e em menor grau da regulação e tecnologia, que podem acelerar ou retardar o novo desenvolvimento.

c) Direção: nessa dimensão, o mercado como um todo continua sendo monitorado para realimentar o processo de desenvolvimento do novo produto. Há também uma atuação importante da matriz do Banco que funciona como agente regulador em todo esse processo, indicando etapas e procedimentos que precisam ser seguidos na confecção do novo bem.

d) Implicações: uma vez terminado o desenvolvimento do novo produto, tanto a regulação quanto o mercado são monitorados para realimentar o processo e permitir adequações e melhorias de produto, ou até mesmo sua descontinuidade. A tecnologia tem papel de coadjuvante nessa dimensão, uma vez que responde principalmente pela operação (dia a dia) do novo produto.

Como um contraponto aos produtos apresentados de sustentabilidade, foi realizada a mesma análise para produtos tradicionais do Banco A. Optouse, neste último caso, pelo CDC tradicional do Banco para fins genéricos. De 
maneira geral, não houve grandes diferenças em relação à esse produto, entretanto pode-se destacar:

a) Forte papel dos concorrentes, uma vez que o produto já está consolidado (tem cerca de 20 anos de existência no mercado) e é amplamente conhecido no mercado. Dessa maneira qualquer alteração ou melhoria incremental produzida por um concorrente é imediatamente aplicada pelos demais players.

b) A tecnologia é vista como um limitador ao invés de um mero viabilizador desse produto, uma vez que pequenas alterações aparentes no produto resultam em grandes investimentos de tempo de recursos para adequação da tecnologia ao produto.

Outro aspecto importante referente ao CDC tradicional diz respeito à sua evolução ao longo de sua existência. Esse produto pouco se modificou em termos que o cliente pudesse perceber (Front Office), entretanto, grandes e significativas foram as alterações ocorridas em seus processos internos ao Banco A (Back Office).

\subsection{Inovação no Banco $B$}

Da mesma maneira que se iniciou a descrição das inovações para o Banco A, no caso do Banco B também vale a pena explorar o conceito e entendimento do Banco quanto à definição de produto bancário. Para o Banco B um produto bancário é "toda e qualquer solução que atenda e satisfaça as demandas e necessidades dos clientes", segundo executivos do Banco.

Por sua vez, o processo de desenvolvimento de novos produtos é uma "necessidade, pois o mercado de varejo é muito dinâmico", segundo entrevistados do Banco, caracterizando a importância do Banco investir continuamente em inovações para sobreviver. .

A inovação e o desenvolvimento de novos produtos no Banco $\mathrm{B}$ a partir do início do Século XXI passam a se tornar uma atividade importante para o banco na medida em que está alinhado com sua estratégia de relacionamento com seus clientes. Além do fato do ambiente em que o Banco está inserido ser fortemente marcado por competição, cujos novos produtos desempenham papel importante na manutenção e conquista de clientes. 
Essa estratégia de relacionamento dá origem a uma série de ações internas no Banco. Uma dessas ações em especial se destaca e ganha ares de inovação quando o banco decide investir em novos canais - com novas possibilidades para os clientes - além da rede de agências.

Paralelamente, o mercado brasileiro de telefones celulares continua crescendo, principalmente com a massificação dos aparelhos pré-pagos. Em 2004, já eram 60 milhões de assinantes, e o mercado demonstrava potencial para superar a marca de 100 milhões de usuários (como de fato aconteceu em janeiro de 2007). A evolução da tecnologia também já indicava que a interação com o cliente, por meio do celular, poderia ser feita de uma forma segura e eficiente, a fim de criar um novo conceito de relacionamento entre o banco e seus clientes. Surge daí um novo conceito de produto para o Banco: "o banco no celular".

O banco no celular foi "uma revolução" em termos de atendimento (canais) - segundo as entrevistas. Por meio dessa inovação, estão disponíveis as operações de consultas de saldo de conta corrente e poupança, extrato de conta corrente, pagamento de boletos de cobrança e contas (água, energia, telefone, etc.), transferências entre contas, DOC/TED, recargas de celulares pré-pagos e empréstimos pessoais. Além da possibilidade de realizar operações bancárias, o cliente também pode ser avisado no celular, via mensagens de texto, sempre que houver movimentação na conta corrente ou cartão de crédito.

Analisado sob as dimensões de difusão das inovações propostas na parte teórica: Determinantes, Ritmo, Direção e Implicações versus Regulação, Mercado e Tecnologia, tem-se o framework, para ambos os produtos, apresentado no anexo. Vale ressaltar os principais aspectos do ponto de vista de regulação, mercado e tecnologia:

a) Regulação: a atuação dos agentes reguladores nesse desenvolvimento foi pouco relevante, visto que a inovação está na oferta de serviços já oferecidos pelo banco, por meio de um novo canal de comunicação.

b) Mercado: o movimento do mercado em direção à mobilidade aliado ao crescimento e desenvolvimento de aplicações via celular agiram como catalisadoras dessa inovação.

c) Tecnologia: o Banco aproveitou o movimento de convergência (dados e voz) que estava ocorrendo para fazer parcerias individuais 
com operadoras de telefonia celular, viabilizando assim essa solução, o que demandou tempo de dedicação da equipe de desenvolvimento para refinar a inovação.

Com relação aos fatores Determinantes, de Ritmo, de Direção e de Implicações das difusões de inovação, tem-se:

a) Determinantes: nessa dimensão tem destaque a oportunidade de estreitamento das relações com clientes de varejo e de novos canais vislumbrada pelo Banco por meio de tecnologia (celular) que estava acessível a diversos públicos.

b) Ritmo: o crescimento do uso de aplicações em terminais ATMs e, posteriormente, Internet agiu como propulsor do desenvolvimento de aplicações para celular aliado a uma série de parcerias e pesquisas para desenvolvimento de aplicações bancárias, particularmente em plataformas JAVA.

c) Direção: essa dimensão é marcada particularmente por ter ocorrido no ano de 2002, no Brasil, com a disponibilidade de aplicações em GSM e todas as suas vantagens em termos de segurança $e$ performance, permitindo a evolução do serviço.

d) Implicações: o banco no celular fez com que o Banco B desenvolvesse um novo canal, alinhado com as tendências e novas exigências de mobilidade e portabilidade do público.

\section{Considerações à Luz da Inovação}

Esta pesquisa proporcionou algumas verificações e conclusões sob a égide da inovação nos estudos de caso apresentados.

\subsection{Inovação e Novos Produtos}

O conceito de inovação está presente de maneira bastante evidente tanto no Banco A quanto no Banco B. Neste Banco existe uma forte orientação da alta direção em fomentar a inovação extrapolando a simples mudança em produtos ou serviços. 
Júlio F. B. Facó • Eduardo H. Diniz • João Mario Csillag

A inovação é fomentada no Banco inclusive para contribuir nas melhorias de processos e atividades que o Banco realiza e que "muitas vezes o cliente não vê", segundo os entrevistados. Dessa maneira, ambos os bancos se esforçam para "a cada dia colocar para o cliente soluções novas ou inovações de produtos", segundo palavras de executivos.

\subsection{Regulação e Inovação}

Interessante notar que para os Bancos $\mathrm{A}$ e $\mathrm{B}$, a característica do mercado ser altamente regulamentado pouco influenciou nas respostas dos entrevistados quando questionados a respeito da possível limitação que os agentes reguladores impunham às suas inovações.

Os entrevistados enfatizaram que os agentes reguladores proporcionam segurança tanto para os Bancos quanto para os clientes, além de prover padronizações e métricas de operação intra e interbancos. E que, apesar das padronizações, o papel principal do agente é a orientação e o fornecimento das condições de contorno. Dessa maneira, as regulamentações pouco influenciam na finalidade ou desenho da inovação, segundo uma aplicação ou nicho específico.

\subsection{Inovação e Segmentação de Clientes}

O segmento que uma inovação pretende atingir é determinante no processo de desenvolvimento do novo produto. Isso ocorre porque para os segmentos top (como é o caso do 'private'), o novo produto tem as características de seu único cliente. Para esses segmentos a sensibilidade do front-office do Banco é fundamental para compreender as necessidades particulares de cada cliente e customizar uma solução para cada um deles.

Os segmentos de middle market ('personal') têm recebido uma atenção maior do Banco A nos meses recentes, seguindo uma orientação da matriz para focar esforços na fidelização desses clientes. Os meios encontrados pelo Banco A para fidelizar esses clientes e "tornar-se o Banco da vida e família do cliente", segundo os gestores de produtos do Banco A, estão no estreitamento do relacionamento e da simultânea geração de novos produtos e soluções o mais customizadas possível (como um modelo de mass customization). Dessa maneira, o feedback do front-office para o back-office 
do Banco é essencial para a adequação de produtos e o fornecimento de um leque cada vez mais variado de soluções para atender às diversas necessidades desse segmento.

Já no Banco B, esse movimento de esforços para fidelizar clientes do middle market também é observado, sendo foco "atuar em todas as necessidades dos clientes", segundo executivos do banco.

Por fim, o mercado de varejo (formado pelos segmentos de 'varejo') tem outras particularidades. Nesse segmento a capacidade de pulverização $e$ distribuição de solução torna-se essencial para o sucesso de uma inovação. Faz-se forte emprego de todos os canais de distribuição e principalmente doa sistemas de TI para diminuir os custos de distribuição e venda do produto, gerando ganhos de escala.

\subsection{Processo e Métricas}

O Banco A e o Banco B possuem um sistema de desenvolvimento de novos produtos bastante rigoroso e com processos, métricas e etapas bem definidas. Particularmente para o Banco A, esses procedimentos ou normatizações internas de elaboração de novos produtos impõem a confecção de um planejamento detalhado acerca do novo produto. Esse detalhamento gera, ao final do processo de desenvolvimento, um projeto com as seguintes características:

a) Desenho completo do produto.

b) Aprovação de todas as áreas do Banco e atendimento às regras dos agentes reguladores.

c) Riscos conhecidos e mensurados, além de uma previsão e comportamento da demanda frente a diferentes cenários.

A partir do detalhamento do novo produto, ele pode e será acompanhado ao longo de seu ciclo de vida, realimentado o processo de criação de produtos novamente.

Um detalhe quanto ao DNP do Banco A se faz necessário. Recentemente o Banco desenvolveu essas métricas e procedimentos por intermédio de uma ferramenta dedicada e proprietária de TI. 
Júlio F. B. Facó • Eduardo H. Diniz • João Mario Csillag

\subsection{Credibilidade e Risco Associado à Inovação}

Quanto à Credibilidade e ao Risco, Associado à Inovação, a opinião do Banco é que a orientação para a sustentabilidade (que tem sido uma forte propulsora de inovações) é uma questão de sobrevivência para o Banco.

Por sua vez, a inovação é um agente que proporciona ao Banco a oportunidade de adequar-se à dinâmica do mercado (em termos de demanda e concorrência), para então acompanhar o ritmo do mercado (em termos de evolução e amadurecimento). Dessa maneira, se não houver inovações, o Banco "fica para trás e perde a credibilidade", segundo as palavras dos responsáveis pelo desenvolvimento de novos produtos. Essa percepção alinhase com o destaque da inovação de produtos de Clark e Wheelwright (1993).

Destaca-se o caso do Banco B cuja Inovação estava fortemente alicerçada na imagem institucional do Banco, em que o banco possui a robusta imagem de uma instituição séria, sólida, segura, tradicional e completa, sendo isso uma "faca de dois gumes", pois não poderia haver insucessos na inovação.

\subsection{Desafios Associados às Inovações}

Um ponto que merece destaque, quanto aos desafios, é registrado no Banco B. Durante o desenvolvimento da inovação, as operadoras de telecomunicações possuíam tecnologias diferentes e não padronizadas, isso levou o Banco a fazer acordos individuais com cada operadora para que pudesse viabilizar o desenvolvimento da inovação.

\section{Conclusões}

Este estudo proporcionou algumas contribuições referentes às atividades de inovação e sua difusão em Bancos de varejo de grande porte que atuam no Brasil. Primeiramente, visto que estudos sobre difusão de novos produtos no setor de serviço são menos frequentes do que no setor de bens físicos, a pesquisa nos Bancos A e B se mostrou oportuna para uma análise de elementos da difusão de suas inovações. 
Outro ponto diz respeito a fatores que influenciam as inovações. Ambos os bancos, adaptaram-se às mudanças que estavam ocorrendo no ambiente dos consumidores. Seja com relação à proliferação de temas ligados a questões ambientais (refletido na inovação do Banco A), ou á convergência de aplicações de tecnologia aliadas à mobilidade e telecomunicações (refletido na inovação do Banco B). Assim, uma nova configuração no comportamento dos consumidores influenciou as inovações em ambos os bancos (SHETH; SISODA, 1998).

Por sua vez, a análise do processo da difusão das três inovações estudadas em profundidade permitiu verificar evidências do papel das quatro dimensões propostas para sua mensuração. Evidenciou-se o papel de agentes determinantes como disparadores das inovações. No caso do Banco A encontrou-se evidência de que a inovação possui aspectos marcantes de ser do tipo "market-pull", enquanto no Banco B é marcante a evidência da inovação ter sido do tipo "technology-push". Quanto ao ritmo, tal como enfatizado por Trajtenberg et al. (1989), sua compreensão se mostrou adequada e necessária para melhor verificar o processo de difusão das inovações. Por sua vez, tanto os aspectos da direção (como os produtos estão se desenvolvendo), quanto os das implicações (quais os impactos que os produtos estão provocando) das inovações são relevantes e imprescindíveis para a compreensão da difusão de cada inovação e se mostraram bastante adequados ao estudo.

Esta pesquisa também oferece uma contribuição metodológica, visto que o Framework de Difusão das Inovações (ilustrado no anexo) pôde ser testado e aplicado em ambos os Bancos paras as duas inovações. Dessa forma, evoluiu-se em relação aos estudos nos quais se baseia este trabalho.

A principal limitação da pesquisa consiste no uso de apenas dois Bancos para aplicar o framework de difusão das inovações. A amostra poderia ser ampliada no futuro para incluir mais bancos e verificar os fatores e dimensões propostos neste estudo. Por fim, o uso de apenas três variáveis (mercado, tecnologia e regulação) para interpor às quatro dimensões sugeridas para mensuração da difusão de inovações, quais sejam: determinantes, ritmo, direção e implicações pode ser uma limitação. Futuras pesquisas poderiam considerar outras variáveis, tais como aspectos de gestão da organização estudada. 


\title{
Innovation Diffusion Process in Banking Products
}

\begin{abstract}
This research is a depth investigation of new products creation and diffusion process in banking area. This research proposes a model to evaluate innovation diffusion in banking products based on a framework with three variables (regulation environment, market and technology) and four dimensions related to innovation diffusion (determinants, rhythm, direction and implications). This research used case studies of retail Banks operating in Brazil. The process of creation, diffusion and sustaining of new three banking products were analyzed in details using the framework proposed. This innovation diffusion process analysis allowed authors to study and test the role of variables and dimensions proposed in the framework. This framework seems to be appropriate for innovations diffusion study.
\end{abstract}

Key-words: Innovation. Diffusion Process. Banking Area.

\section{Referências}

ANDREASSI, T. Porque é tão difícil inovar em serviços. Gazeta Mercantil, São Paulo, p. 2, 7 de janeiro de 2002.

ASSAF, A. Mercado Financeiro. São Paulo: Atlas, 1999.

BARBIERI, J. C.; SIMANTOB, M. A. Organizações Inovadoras do Setor

Financeiro: teoria e casos de sucesso. São Paulo: Saraiva, 2009.

BARRAS, R. Interactive innovation in financial and business services: the vanguard of the service revolution. Research Policy, 19, p. 215-237, 1990.

BÁTIZ-LAZO, B; WOLDESEnBET, K. The Dynamics of Product and Process Innovation in UK Banking. Economics Working Paper Archive EconWPA, 2004.

BROWN, S. L.; EISENHARDT, K. M. Product development: past research, present findings, and future directions. Academy of Management Journal, 20(2), 343-378, 1995. 
BETZ, F. Strategic technology management. USA: McGraw-Hill Engineering and Technology Management, 1993.

BUZZACHI, L.; COLOMBO, M.; MARIOTTI, S. Technological regimes and innovation in services: the case of the Italian banking industry. Research Policy, 24, p. 151-168, 1995.

CHAKRAVORTI, S.; KOBOR, E. Why invest in payment innovations? Federal Reserve Bank of Chicago, Emerging Payments Occasional Papers Series, june/2003.

CLARK, K. B.; FUJIMOTO, T. Product development performance: strategy, organization and management in the world auto industry. Boston, Mass.: HBS Press, 1991.

CLARK, K. B.; WhEELWRIGHT, S. C. Managing New Product and Process Development. New York: The Free Press, 1993.

CLAUSING, D. Total Quality Development. New York: Asme Press, 1994.

COOPER, R.; EASINGWOOD, C.; EDGETT, S.; KLEINSCHMIDT, E.;

STOREY, C. What Distinguishes the Top Performing New Products in Financial Services. Journal of Product Innovation Management, v. 11, n. 4, p. 281289, Sep., 1994.

CORRÊA, H. L.; CAON, M. Gestão de Serviços. São Paulo: Atlas, 2002.

CORRÊA, H. L.; CORRÊA, C. A. A critical analysis of the product-service dichotomy in operations management. Accepted for publication in Latin America Business Review - forthcoming, 2006.

DINIZ, E.; FACÓ, J. F. B.; CSILLAG, J. M. Inovação em Produtos Bancários, 2007. In: BERNARDES, R.; ANDREASSI, T. Inovação em Serviços Intensivos em Conhecimento. São Paulo: Saraiva, 2007.

EDWARDS, P. N. From impact to Social Process: computers in society and culture. In: Handbook of Science and Technology Studies. Edited by Jasanoff, Sheila; Markle, Geral E.; Pettersen, James C.; Pinch, Trevor. Sage Publications, 1995.

ERIKSSON, K. The interrelatedness of technology, environment and organization structure: a study of differentiation and integration in banking. Reprocentralen, HSC, Uppsala. 1994. 
Júlio F. B. Facó • Eduardo H. Diniz • João Mario Csillag

FACÓ, J. F. B. O Processo de Desenvolvimento de Novos Produtos em Ambientes de Informação Intensiva: Uma análise exploratória aplicada ao setor de bancos de varejo do Brasil. Dissertação (Mestrado em Administração). EAESP.FGV. São Paulo, 2006.

FEBRABAN. Dados e Estatística Bancária. Disponível em: < http:// www.febraban.org.br/>. Acesso em: 15 nov. de 2008.

GONÇALVES, J. E. L. Os impactos das novas tecnologias nas empresas prestadoras de serviços. Revista de Administração de Empresas, São Paulo: FGV, v. 34, n. 1, p. 63-81, jan./fev., 1994.

GRIFFIN, A. PDMA Research on New Product Development Practices: Updating Trends and Benchmarking Best Practices. Journal of Product Innovation Management, v. 14, pp .429-458, 1997.

GRISCI, C. L. I.; BESSI, V. G. Modos de trabalhar e de ser na reestruturação bancária. Sociologias, Porto Alegre, ano 6, n. 12, jul./dez., p. 160-200, 2004.

HANNA, N.; GUY, K.; ARNOLD, E. The diffusion of information technology: experience of industrial countries and lessons for developing countries. World Bank: Discussion Papers, p. 281, 1995.

HUSSEY, D. E. Creativity, innovation and strategy. In: The Innovation Challenge. Edited by David E. Hussey. England: John Wiley \& Sons. 1997.

LEITE, J. C. Tecnologia e Organizações: um estudo sobre os efeitos da introdução de novas tecnologias no setor bancário brasileiro. Tese - FEA, USP, São Paulo: 1996.

LIMA, G. T. Evolução recente da regulação bancária no Brasil. Temas de Economia Internacional, Ministério da Fazenda, Secretaria de Assuntos Internacionais. Brasília: dezembro de 2003.

McKENDRICK, D. Sources of imitation: improving bank process capabilities. Research Policy, 24, p. 783-802, 1995.

MCLOUGHLIN, I.; HARRIS, M. Understanding innovation, organizational change and technology. In: Innovation, organizational change and technology. The management of technology and innovation series. International Thompson Business Press. 1997. 
METTERS, R.; KING-METTERS, K; PULLMAN, M. Successful Service Operations Management. South-Western, 2003.

PIRES, H. F. Reestruturação Inovativa e Reorganização das Instituições Financeiras do Setor Privado no Brasil. Revista Geouerj, Rio de Janeiro, n. 2, pp.65-79, 1997.

POPCORN, F. O Relatório Popcorn: centenas de idéias de novos produtos, empreendimentos e novos mercados. Rio de Janeiro: Campus, 1994.

ROGERS, D. The Future of American Banking: managing for change. New York: McGraw-Hill, 1993.

ROGERS, E.; SCHOEMAKER, F. Communication of Innovations: a cross cultural approach. USA: Free Press, 1971.

ROSALES, R. Marco Jurídico para as Instituições de Micro-crédito. Seminário Internacional BNDES Micro-finanças, Rio de Janeiro: maio de 2000.

SHETH, J. N.; SISODA, R. S. Consumer Behavior in the Future, 1998. In: PETERSON, R. A. Electronic Marketing and the Consumer. EUA: Sage Publications, 1997, 193p.

SCHILLING, M. A.; HILL, C. W. L. Managing the new product development process: strategic imperatives. Academy of Management Executive, v. 12, n. 3, p. 67-81, Ago. 1998.

SLACK, N.; LEWIS, M. Operations Strategy. London: Prentice Hall, 2002.

STERN, L. W.; EL-ANSARY, A. I.; COUGHLAN, A. T. Marketing Channels, 5. ed. EUA: Prentice Hall, 1996, 575 p.

THE BANKER. The Top One Thousand World Banks. London: The Banker, Financial Times Business, july, 2005.

TIGRE, P. B. Gestão da Inovação: a economia da Tecnologia no Brasil. Rio de Janeiro: Elsevier, 2006.

TRAJTENBERG, M.; YITZHAKI, S. The diffusion of innovations: a methodological reappraisal. Journal of Business \& Economic Statistics, v. 7, iss. 1, p. 35-47, january, 1989. 
VAN DE VEN, A. Central Problems in the Management of Innovation.

Management Science, v. 32, p. 590-607, 1986.

WILNER, A. Funil financeiro. GVExecutivo, v. 4, n. 4. nov. 2005/jan. 2006.

YIN, R. K. Case Study Research: design and methods. USA: Sage

Publications Inc., 1988.

\section{Anexo A - Framework de difusão das inovações para os produtos: CDC Socioambiental e Operações de Crédito Carbono}

\begin{tabular}{|c|c|c|c|}
\hline & Regulação & Mercado & Tecnologia \\
\hline 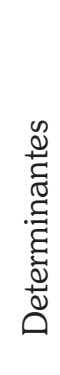 & $\begin{array}{l}\text { Agentes: } \mathrm{BCB} \text { (principal agen- } \\
\text { te) e Ministério do Meio Am- } \\
\text { biente; } \\
\text { Papel Passivo; } \\
\text { Obs. Existe uma regulamen- } \\
\text { tação padrão para produtos } \\
\mathrm{CDC} \text {, entretanto a finalidade } \\
\text { o Banco decide. }\end{array}$ & $\begin{array}{l}\text { Fatores internos ao } \\
\text { Banco: política de } \\
\text { sustentabilidade na es- } \\
\text { tratégia. } \\
\text { Fatores externos: a) De- } \\
\text { manda inicialmente } \\
\text { imatura, b) concorrentes } \\
\text { sem produtos similares. }\end{array}$ & $\begin{array}{l}\text { Papel coadjuvante. Atua } \\
\text { com mais presença nas } \\
\text { questões de distribuição e } \\
\text { divulgação dos produtos } \\
\text { nos diversos canais do ban- } \\
\text { co. A TI funciona como um } \\
\text { meio e não como um } \\
\text { limitador nesse processo. }\end{array}$ \\
\hline 壳 & $\begin{array}{l}\text { Agentes: } \mathrm{BCB} \text { (principal agen- } \\
\text { te) e Ministério do Meio Am- } \\
\text { biente (Créd. Carbono); } \\
\text { Papel Passivo: O BCB exige } \\
\text { apenas indicadores de } \\
\text { inadimplência dos CDC. }\end{array}$ & $\begin{array}{l}\text { Acompanhamento de } \\
\text { cenários e demanda. } \\
\text { Avaliações de risco e } \\
\text { inadimplência entre ou- } \\
\text { tros indicadores. } \\
\text { Monitoramento da con- } \\
\text { corrência } \\
\text { Mais } 10.000 \text { contratos } \\
\text { de CDC e diversas op. } \\
\text { de crédito carbono. }\end{array}$ & $\begin{array}{l}\text { Papel: Datamining, } \\
\text { Database para a busca de } \\
\text { relações de consumo e de- } \\
\text { manda para ações mais } \\
\text { efetivas e campanhas ou } \\
\text { promoções pontuais. } \\
\text { Abrangência: TI voltada } \\
\text { para a operação (dia a dia) } \\
\text { do produto. }\end{array}$ \\
\hline
\end{tabular}

Fonte: elaborado pelos autores 


\begin{tabular}{|c|c|c|c|}
\hline & Regulação & Mercado & Tecnologia \\
\hline 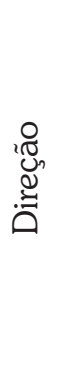 & $\begin{array}{l}\text { Matriz do Banco na Europa é } \\
\text { o principal agente na defini- } \\
\text { ção do processo de desenvol- } \\
\text { vimento de novos produtos. } \\
\text { BCB não determina o proces- } \\
\text { so ou o fluxo de desenvolvi- } \\
\text { mento de um produto. }\end{array}$ & $\begin{array}{l}\text { Estimativa de demanda } \\
\text { (viabilidade, custos de } \\
\text { operação, overhead, } \\
\text { custos de tecnologia, ris- } \\
\text { cos e cenários). }\end{array}$ & $\begin{array}{l}\text { Papel: viabilizadora dos } \\
\text { produtos. } \\
\text { Atuação: a) CDC pouca } \\
\text { atuação - conceito já con- } \\
\text { solidado; b) Op. Créd. Car- } \\
\text { bono determinante, neces- } \\
\text { sário alinhamento com } \\
\text { matriz do Banco A. }\end{array}$ \\
\hline 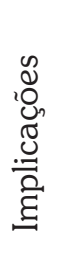 & $\begin{array}{l}\text { Agentes: BCB e Matriz do } \\
\text { Banco. } \\
\text { Papel BCB - regulamentação } \\
\text { nova; papel Matriz - } \\
\text { descontinuidade ou criação de } \\
\text { nova linha de produtos. }\end{array}$ & $\begin{array}{l}\text { Papel da demanda e da } \\
\text { c o n c o r r ê n c i a : } \\
\text { Monitoramento e ade- } \\
\text { quação de ações e cam- } \\
\text { panhas específicas. }\end{array}$ & $\begin{array}{l}\text { Papel: Pode viabilizar ade- } \\
\text { quações, melhorias ou no- } \\
\text { vos produtos. }\end{array}$ \\
\hline
\end{tabular}

Fonte: elaborado pelos autores

\section{Anexo B - Framework de difusão das inovações para os produtos: Banco no Celular}

\begin{tabular}{|c|c|c|c|}
\hline & Regulação & Mercado & Tecnologia \\
\hline 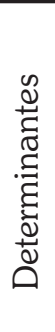 & $\begin{array}{l}\text { Agentes: BCB e ANATEL. } \\
\text { Papel: A atuação dos agentes } \\
\text { reguladores nesse desenvolvi- } \\
\text { mento foi pouco relevante, } \\
\text { pois as regras existem não } \\
\text { impediam o desenvolvimento } \\
\text { da inovação; }\end{array}$ & $\begin{array}{l}\text { Oportunidade de estreita- } \\
\text { mento das relações com } \\
\text { clientes de varejo e de } \\
\text { novos canais; }\end{array}$ & $\begin{array}{l}\text { Operadoras de telefonia } \\
\text { (com forte crescimento de } \\
\text { mercado) já esboçavam } \\
\text { meios para auferir receitas } \\
\text { adicionais com a transmis- } \\
\text { são não apenas de voz, mas } \\
\text { de dados entre usuários. }\end{array}$ \\
\hline 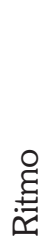 & $\begin{array}{l}\text { Agentes BCB e ANATEL } \\
\text { Papel: Pouco expressivo. }\end{array}$ & $\begin{array}{l}\text { O crescimento do uso de } \\
\text { aplicações em terminais } \\
\text { ATMs. Posteriormente } \\
\text { em Internet. Em seguida } \\
\text { aplicações para celular. }\end{array}$ & $\begin{array}{l}\text { O Banco já mantinha con- } \\
\text { vênios para o desenvolvi- } \\
\text { mento de aplicações co- } \\
\text { merciais para inovações } \\
\text { tecnológicas; }\end{array}$ \\
\hline
\end{tabular}

Fonte: Elaborado pelos autores e adaptado de Barbieri e Simantob (2009) 


\begin{tabular}{|c|c|c|c|}
\hline & Regulação & Mercado & Tecnologia \\
\hline 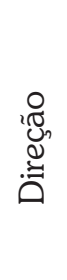 & $\begin{array}{l}\text { Agentes BCB, ANATEL e Di- } \\
\text { reção do Banco. } \\
\text { Papel: Significativo quando } \\
\text { da aplicação das regras rela- } \\
\text { cionadas à tecnologia GSM } \\
\text { (ANATEL) }\end{array}$ & $\begin{array}{l}\text { Forte reposicionamento } \\
\text { do Banco em sua estra- } \\
\text { tégia de Marketing e de } \\
\text { canais. }\end{array}$ & $\begin{array}{l}\text { Ano de 2002: disponibilida- } \\
\text { de de aplicações em GSM, } \\
\text { permitindo evolução dos } \\
\text { serviços. }\end{array}$ \\
\hline 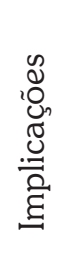 & $\begin{array}{l}\text { Agentes BCB e ANATEL } \\
\text { Papel: Pouco Expressivo. }\end{array}$ & $\begin{array}{l}\text { Desenvolvimento de um } \\
\text { novo canal; } \\
\text { Contribuiu para a valo- } \\
\text { rização da marca do } \\
\text { Banco }\end{array}$ & $\begin{array}{l}\text { Fortíssima atuação e pre- } \\
\text { sença do Banco na mídia; } \\
\text { Avanço no uso das soluções } \\
\text { de negócios baseadas em } \\
\text { SMS ("short message } \\
\text { service"), }\end{array}$ \\
\hline
\end{tabular}

Fonte: Elaborado pelos autores e adaptado de Barbieri e Simantob (2009) 